\title{
AN AGGRESSIVE CENTRAL GIANT CELL GRANULOMA OF THE MAXILLA: DIAGNOSTIC DILEMMA, PRECISE DIFFERENTIAL DIAGNOSIS AND SUCCESSFUL TRADITIONAL SURGICAL APPROACH: A CASE REPORT
}

\author{
Abdurahman Musbah Elmezwghi*, Nuri Mustafa Alarabi**, Abeer Hussein Elsagali***, \\ Salma S. Mo Zariba ${ }^{* * * *}$, Najia Emhemed BenGharbia ${ }^{* * * * *}$ and Nesrin Hassan Musa ${ }^{* * * * * *}$
}

\begin{abstract}
Central Giant Cell Granuloma (CGCG) is a benign, proliferative, intraosseous and nonodontogenic lesion of unknown etiology accounting for approximately $10 \%$ of all benign lesions of the jawbones. Lesion usually occurs in patients younger than 30 years, is more common in females than males, and is more common in mandible than maxilla. The clinical feature of CGCG ranges from a slow growing asymptomatic swelling to a rapidly enlarging aggressive lesion. CGCG of the jaws are histologically benign lesions characterized by the presence of giant cells in the richly vascularized stroma of the spindle cells. Differential diagnosis should be performed with other lesions that have multinucleated giant cells (MGCs). Definitive diagnosis relies on correct interpretation of clinical, radiographical and histopathological data. The treatment of CGCG ranges from curettage to resection. Alternative treatments are worthy of consideration, although surgical excision remains the treatment of choice.
\end{abstract}

The aim of this presented case highlights a diagnostic challenge of an aggressive CGCG arising from the maxilla and to discuss a precise differential diagnosis, as well as the surgical approach and follow up which is decisive for successful conventional surgical treatment with no lesion recurrence.

KEYWORDS: Central giant cell granuloma, aggressive and non-aggressive form, differential diagnosis, traditional surgical treatment, Recurrence follows up.

\footnotetext{
* Oral Pathology Dept. Faculty of Dentistry. University of Tripoli. Tripoli-Libya.

** Oral and Maxillofacial Dept. Faculty of Dentistry. University of Tripoli. Tripoli -Libya.

*** Oral and Maxillofacial Surgery Dept. Faculty of Dentistry. University of Tripoli. Tripoli-Libya.

**** Oral maxillofacial Surgery Dept. Faculty of Dentistry. University of Tripoli. Tripoli-Libya.

***** Oral and Maxillofacial Dept. Faculty of Dentistry. University of Tripoli. Tripoli-Libya.

******* Oral and Maxillofacial Surgery Dept. Faculty of Dentistry. University of Tripoli. Tripoli-Libya.
} 


\section{INTRODUCTION}

Central giant cell granuloma (CGCG) is an uncommon locally destructive, but benign lesion that occurs in the craniofacial region especially in jaw bones. (1) Jaffe in 1953 termed these lesions "Giant Cell Reparative Granulomas", however later the term "Reparative" was abolished as not all the lesions were reported to be self-healing in nature. (2) The CGCG is a non-odontogenic condition that represents around $10 \%$ of all benign jaw lesions. It has an incidence of $0.0001 \%$ in the general population. ${ }^{(3)}$ CGCG shows a female predilection (2:1), is more common in the mandible than maxilla, with the anterior mandible the most common location and occurs predominantly before the age of 30 years. ${ }^{(4)}$ The origin of CGCG is uncertain. Local trauma, inflammation, intraosseous bleeding and genetic abnormalities have been regarded as possible causes, but a unique explanation has not gained a wide acceptance. ${ }^{(5)}$ The clinical behavior of CGCG varies from non-aggressive a slowly asymptomatic swelling to an aggressive lesion that manifests with pain, cortical perforation, and root resorption. (6) There is a strong association between multiple lesions and disorders such as hyperparathyroidism, Noonan like multiple giant cell lesion syndrome, giant cell tumor (GCT), cherubism and Paget's disease. ${ }^{(7)}$ The histological features of CGCG are defined by the WHO as an intraosseous lesion consisting of fibrous tissue containing multiple foci of hemorrhage, aggregations of (MGCs) and occasionally trabeculae of bone. ${ }^{(8)}$ MGCs shows smaller number of nuclei, which are uniformly distributed, (9) such cells have intermediate characteristics of osteoclasts and macrophages. ${ }^{(10)}$ Both aggressive and non-aggressive appear same histologically. (11) Immunohistochemistry is of limited use in differentiation between aggressive and non-aggressive lesions. ${ }^{(12)}$

The radiological appearance of CGCG is variable. Usually the lesion appears as a unilocular or multilocular radiolucency. It may be well-defined or ill-defined and shows variable expansion and destruction of the cortical plate. The radiological appearance of the lesion is not pathognomonic and may be confused with that of many other lesions of jaws. ${ }^{(13)}$ Small unilocular lesions can be confused with other chronic periapical lesions as cysts or granuloma or apical scar. Whereas, multilocular presentation of CGCG cannot be distinguished radiographically from ameloblastomas, $\mathrm{OKC}$ or other multilocular lesions. ${ }^{(14)}$

Clinical and radiographic features are not definitive diagnosis in CGCG. ${ }^{(15)}$

Although, the final diagnosis eventually rests on histopathology. ${ }^{(16)}$ It is fundamental that all the patients with suspected CGCG, should have right serum levels of calcium, phosphate and alkaline phosphatase, to exclude the possibility of hyperparathyroidism (HPT) ${ }^{(17)}$ Furthermore, The differential diagnosis of CGCLs includes the peripheral giant cell granuloma (PGCG) that extends deeper to the bone, and giant cell tumor of bone (GCT). ${ }^{(18)}$

CGCGs have traditionally been treated surgically either by curettage or resection. ${ }^{(19)}$ Nonaggressive lesions respond well to curettage, but aggressive lesions have higher recurrence rate after enucleation or curettage. ${ }^{(20)}$ Recurrence rates have been reported to range between $11 \%$ and $49 \%$ for curettage alone for non-aggressive subtypes and $72 \%$ for aggressive subtypes . ${ }^{(21)}$

In recent years, surgical and medical combination treatment protocol consisting of curettage with safety margins and preservation of vital structures has been introduced. ${ }^{(22)}$ An alternative non-surgical treatments include intralesional injections of steroids, calcitonin, and bisphosphonates, which inhibit osteoclastic activity and alpha interferons due to its anti-angiogenic effects. (23) The main drawback to these nonsurgical approaches is the need for continual extended or repeated injection over a prolonged time period. ${ }^{(24)}$ 
It remains to use standardized radiographic follow up is the most sensitive and useful measure for determining bone healing and recurrence of these lesions. ${ }^{(7)}$

\section{Case Report}

A 28 years old Libyan woman was referred to the Oral and Maxillofacial Surgery Department, Faculty of Dentistry, University of Tripoli, with the chief complain of swelling on the right side of her face for 2 months. The swelling has gradually enlarged to the present size. There was no relevant medical history of any systemic disease or any drug allergy. Upon extra oral examination, facial asymmetry was seen with a localized solitary swelling raising the right canine fossa and lip of the same side which was confined between ala of the nose and nasolabial fold. The overlying skin was normal. On extra-oral palpation, swelling appeared to be nontender and firm in consistency, with non-palpable regional lymph nodes. The federation Dentaire Internationale (FDI) tooth numbering system was used to record the related teeth in the area. On intraoral examination, there was obliteration of the upper right labial vestibule, the teeth related to the swelling were vital. The swelling was firm and extended from the mesial aspect of the root of 11(FDI) to the mesial aspect of root of 13 (FDI). According to the history and clinical examination, our provisional diagnosis was radicular cyst (RC). On radiographic examination, Orthopantomograph (OPG) view showed well-defined periapical unilocular radiolucent area involving the apices of 11(FDI) and of 12 (FDI) (Fig.1). On cone beam computed tomography (CBCT), the $3 \mathrm{D}$ view showed bony cavity involving the apices of both teeth upto the floor of the nose (inferio-superiorly) and from the nasal spine to the lateral aspect of the canine fossa, measuring approximately $2 \mathrm{~cm}$ $\mathrm{x} 1.5 \mathrm{~cm}$. There was slight perforation of the nasal floor and complete perforation of the labial cortical plate (Fig.2). On coronal view there was clear soft tissue swelling and slight perforation of nasal bone (Fig.3). Histopathologic examination showed areas of hemorrhage and the MGCs were clustered around the areas of hemorrhage. Osteoid was also identified. (Fig.4 a\&b) Routine lab investigations including serum calcium, phosphorous and alkaline phosphatase were within normal ranges. Since our case was a solitary lesion, other syndromic lesions were ruled out. In the absence of an obvious cystic lesion, and according to all previous clinical, radiographical, histopathological and laboratory investigations findings. So the definitive diagnosis of CGCG was given. $2 \mathrm{~mm}$ above the mucogingival line and parallel to it an approximately $20 \mathrm{~mm}$ linear mucosal incision was performed from the mid of the upper right canine to the labial frenum, we found most of the lesion bulging out of jaw bone, the lesion was separated gently from the opposing mucosa with dissecting scissor (Fig.5 and Fig.6). The tumor was enucleated as one piece completely from the bony cavity, followed by curettage with debridement and flap suturing was done (Fig.7). Postoperative clinical and radiographic follow-up was done for next 2 years. There was a regression of the lesion size, progressive osseous regeneration and complete healing with no evidence of the lesion recurrence was established (Fig.8 a\&b).

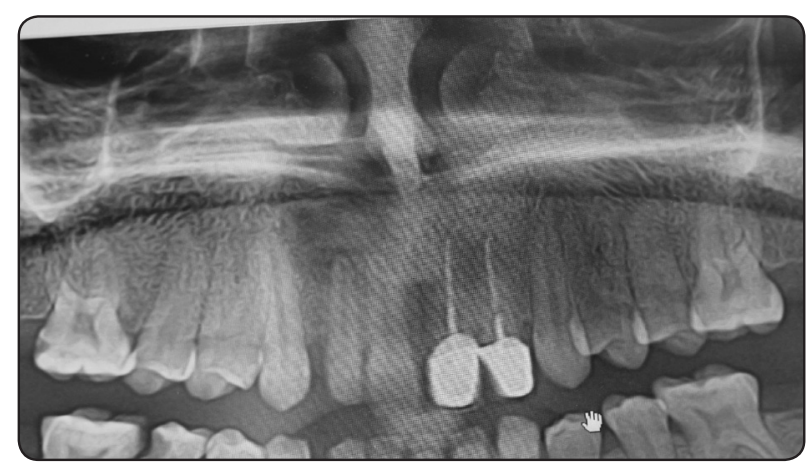

Fig. (1) Preoperative OPG showed well-defined periapical unilocular radiolucent area Involving the apices of 11 (FDI) and 12 (FDI). 


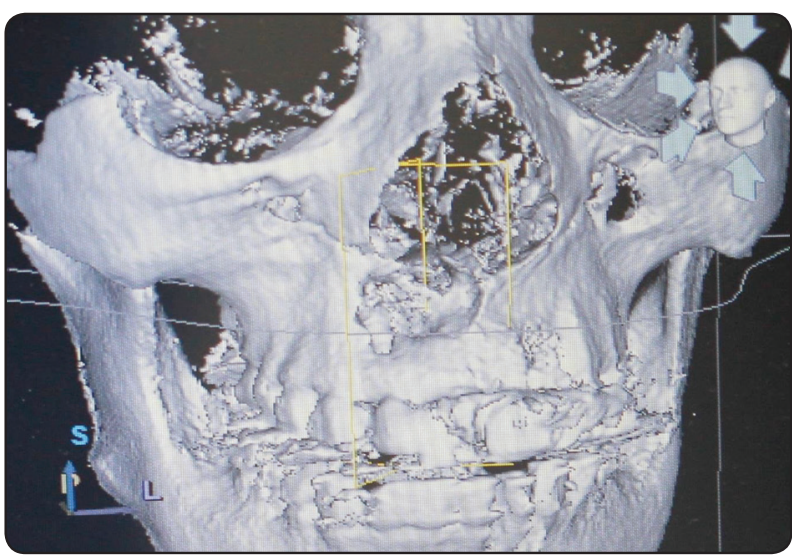

Fig. (2) CBCT, 3D view showed a bony cavity measuring approximately $2 \mathrm{~cm} \times 1.5 \mathrm{~cm}$. There were slight nasal floor and complete labial cortical plate perforation.

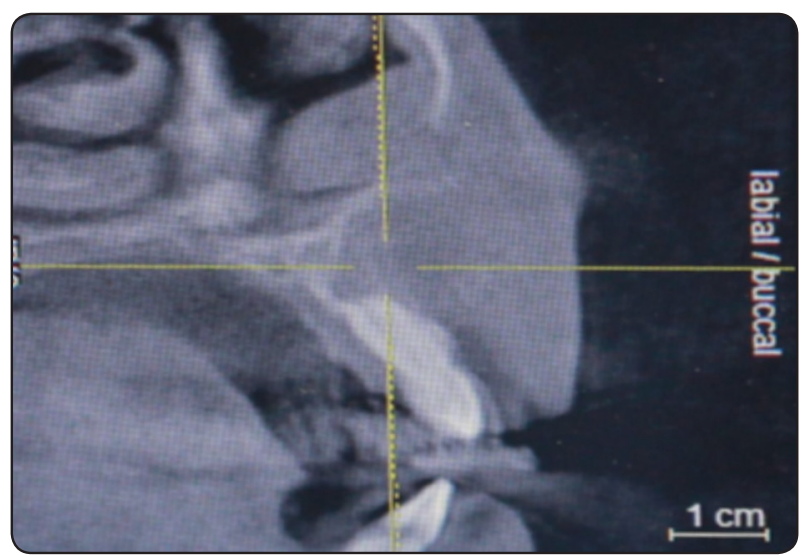

Fig. (3) CBCT, Coronal view showed clear soft tissue swelling with slight perforation of nasal bone.

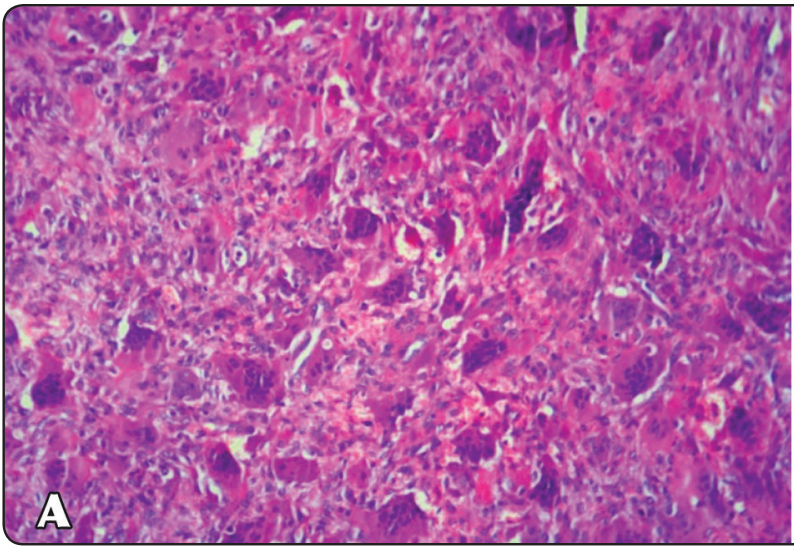

Fig. (4 a) A photomicrograph showing areas of hemorrhage and the MGCs were clustered around the areas of hemorrhage (H\&E X10).

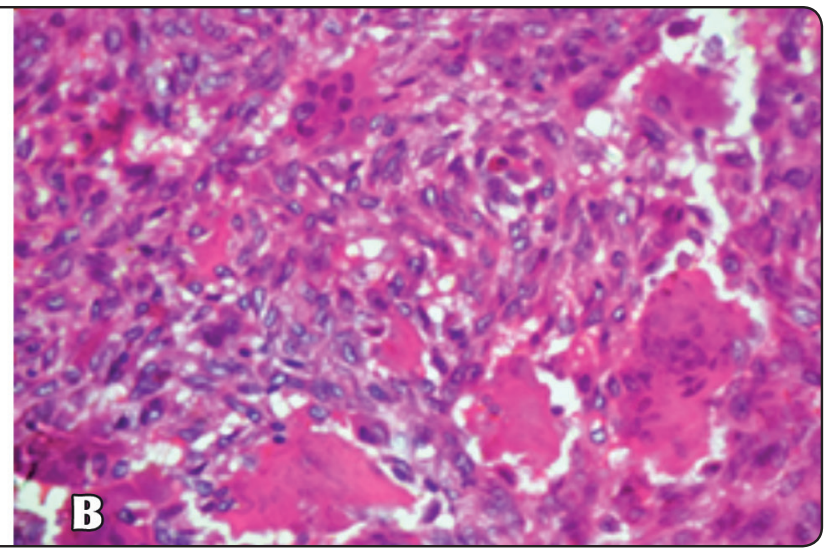

Fig. (4 b) A photomicrograph showing multinucleate osteoclastlike giant cells with numerous nuclei (H\&E x20).

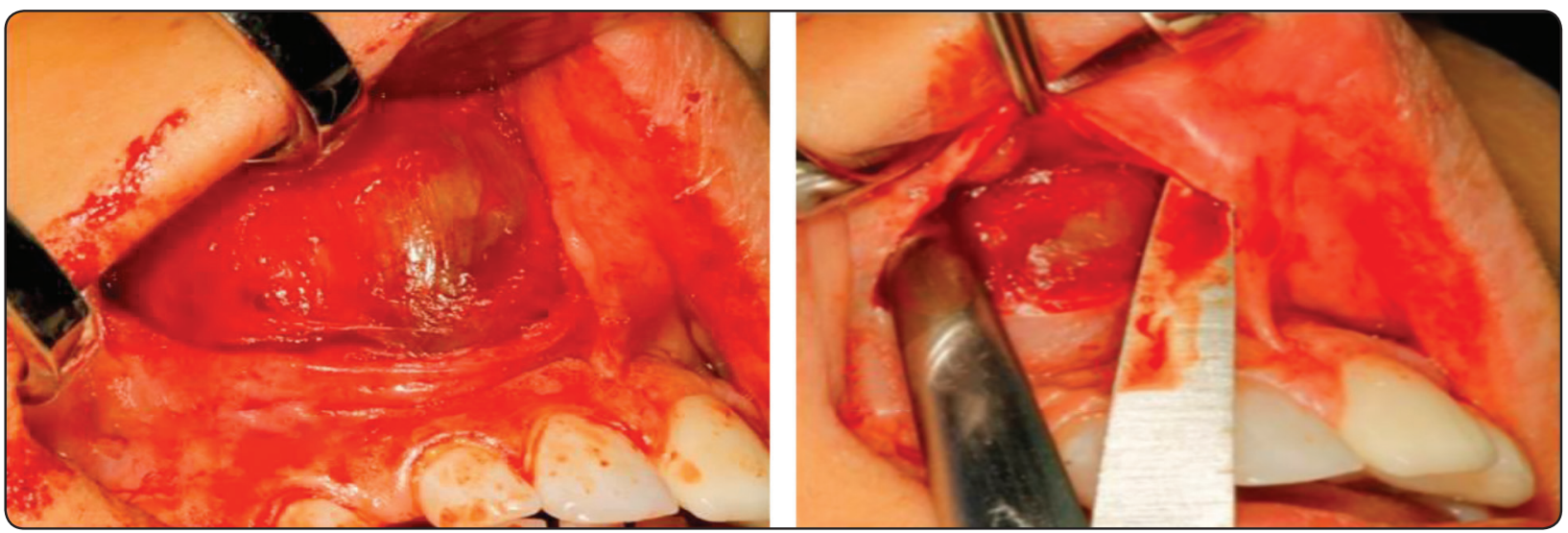

Fig. (5\&6) Intra-oral photograph view showed linear mucosal incision was performed, note most of the lesion bulging out of the jaw bone and the lesion was separated gently from the opposing mucosa with dissecting scissor. 


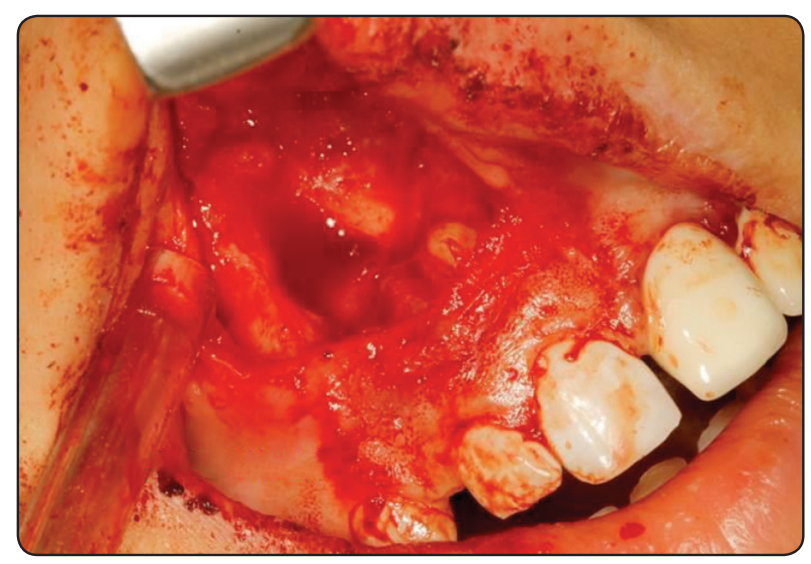

Fig. (7) Intra-oral photograph view showed the tumor was enucleated as one piece completely from the bony cavity and curettage was done.

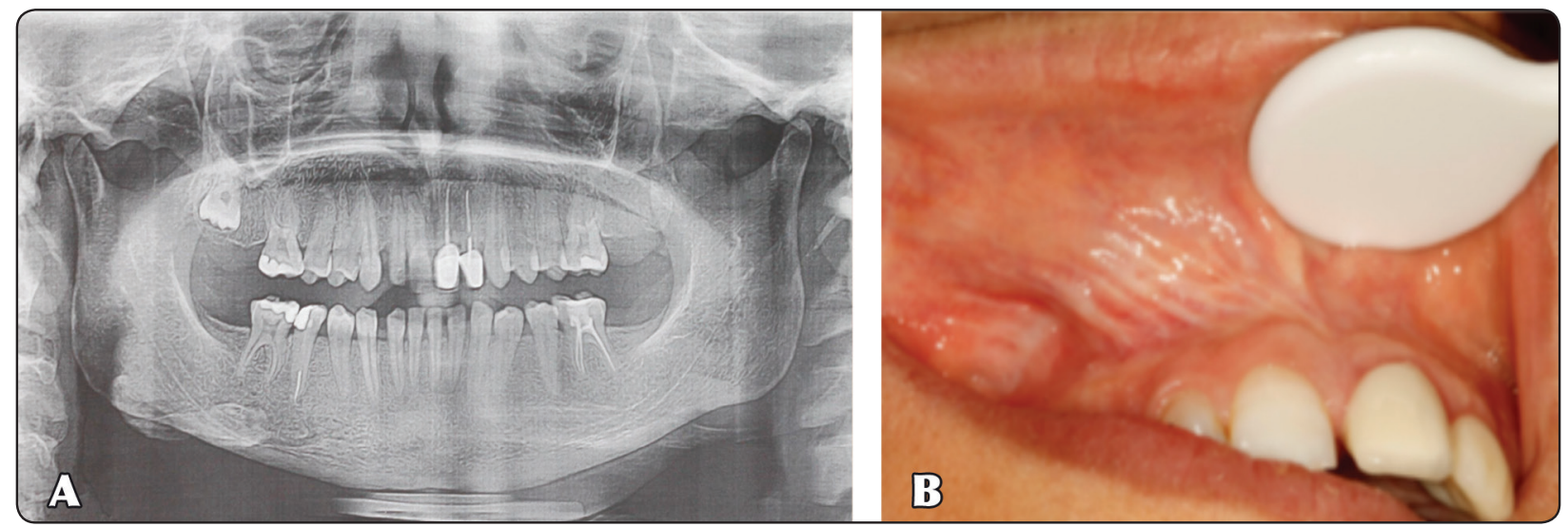

Fig. (8 a\&b) After 2 years of radiographic and clinical follow up OPG showed elimination of the lesion, progressive osseous regeneration and complete healing with no evidence of recurrence.

\section{DISCUSSION}

CGCGs are locally aggressive nonneoplastic lesions. ${ }^{(25)}$ They tend to occur in young patients, under the age of 30 with a slight predilection for women. (26) Our patient was 28 years old, young adult woman. It occurs twice as frequently in the mandible than the maxilla, with restriction to the tooth-bearing areas of the jaw. In the maxilla, it favors the anterior region, while in the mandible, it commonly occurs anterior to the first molar tooth and extends to cross the midline. ${ }^{(27)}$ The presented lesion was located in the region of anterior right maxilla. It was consistent with many previous studies regarding site, age and gender at the time of diagnosis.
Clinically, the lesion may vary from an asymptomatic lesion that grows slowly without expansion seen in this case, to an aggressive, painful process followed by root resorption, cortical bone destruction, and extension into the soft tissue. (28) Our presented case, her chief complain was a diffuse non-tender hard bony swelling, with slight facial asymmetry. It was coincide with many previous reported cases.

Radiographic appearance of GCG may be unilocular or multilocular, with either welldefined or less-defined margins. Root resorption and tooth displacement may also be evident. (29) Although radiographic features of CGCG are not pathognomonic. There were similar findings in the OPG view of our patient, which revealed 
well-defined periapical unilocular radiolucent area involving the apices 11 (FDI) and 12 (FDI) with no evidence of root resorption or tooth displacement. (Fig.1) In agreement with many previously reported cases. Histological features are characterized by loose fibrillar connective tissue stroma interspersed with proliferative fibroblasts and small capillaries with prominence of MGCs of different sizes. Foci of new trabeculae of osteoid/bone are seen usually around the lesion. ${ }^{(30)}$

The classical histopathologic features observed in this case confirmed the diagnosis of typical CGCG and similar to other previous studies. Based on the clinical and radiographic features CGCG is of two types, namely- aggressive lesions and non-aggressive lesions. ${ }^{(31)}$ Nonaggressive lesions are characterized by no symptoms, slow growth, absence of cortical perforation, and low recurrence rate. ${ }^{(1-3)}$ The aggressive pattern is less common characterized by large lesions with swelling of the jaw, rapid growth, pain, paresthesia, cortical bone perforation or thinning, root resorption, and high recurrence rate. ${ }^{(32)}$ However, in this presented case there was history of rapid growth. Solitary localized firm swelling on intra-oral examination. Furthermore, clear soft tissue swelling, slight nasal floor and complete labial cortical plate perforation were evident in CBCT, 3D and coronal views (Fig 2 and 3). All these clinical and radiographic findings in our case were coincided with an aggressive form feature, which in agreement with many previous studies, especially Mezzour et al., $2017^{(33)}$, Bonolis et al. $2017^{(34)}$ and Elitsa $2013^{(35)}$ who reported that an aggressive lesion is characterized by one or at least three of the above mentioned aggressive form features. The final diagnosis is based on its histopathological features, despite the clinical and radiological features are not pathognomonic ${ }^{(36)}$ and often confused with other jaw lesions that pose challenge to oral diagnostician. ${ }^{(37)}$ In our presented case, the provisional diagnosis was considered to be RC. A detailed review of the patient's past medical and dental histo- ries, clinical aspects, specific radiographic findings and histopathologic appearance represent important steps in the definite diagnostic process and may prevent a diagnostic dilemma. ${ }^{(38)}$ According to the above fundamental diagnostic rules, in our reported case the final diagnosis of an aggressive CGCG of the maxilla was confirmed.

Regarding differential diagnosis, small unilocular lesions may be radiographically confused with granulomas and periapical cysts. When they are multilocular, they may be confused with ameloblastomas, ${ }^{(39)}$ or keratocystic odontogenic tumor (KOT). ${ }^{(40)}$

Regarding to the clinical / radiographical assessment of the present case, the differential diagnosis can include a periapical cyst (but the teeth involved in the lesion were vital with no detected carious lesion). Ameloblastomas, the most common age of occurrence is fourth to fifth decades of life, (but the age of our patient was 28 years old, and commonly forms in the posterior mandible (but our reported case the lesion was located in the anterior maxilla). KOT, most frequently in the posterior alveolar ridge or angle of mandible and postoperative recurrence is common (but this presented lesion was located in the anterior maxilla and no postoperative lesion recurrence was evident.

Numerous giant cell rich lesions of jaws could be considered in the differential diagnosis. ${ }^{(41)}$ They include cherubism, PGCG. GCT, aneurysmal bone cyst (ABC), traumatic bone cyst (TBC) and jaw tumour of hyperparathyroidism. ${ }^{(42)}$

Most of the histologic findings reveal fibrous connective tissue and normal bone, the lesion may exhibit area of vascularity, fibrin, erythrocytes and occasional giant cells adjacent to the bone surface of the jaw

The histopathological differential diagnosis for central giant cell lesion includes cherubism which develops as a bilaterally symmetrical 
expansile lesion near the angle of the mandible. Radiographically, it appears as multilocular radiolucencies (but in the present, it was unilateral well-defined unilocular periapical radiolucent area in the anterior maxilla). For PGCG, exclusively gingival located usually anterior to first molars and spongy in consistency with its etiology probably due to trauma or chronic irritation. Furthermore, the presence of the MGCs-free zone in the connective tissue stroma (but in this presented case the lesion was endosteal and firm in consistency of unknown etiology and the MGCs were scattered throughout connective tissue stroma i.e. no MGCs free zone was evident). GCT, it is an extragnathic tumor is more likely to cause variable severity of pain, rare and occurs in a slightly older age group (but our patient did not give any history of pain except slight tenderness on palpation and she was 28 years old at the time of diagnosis. Furthermore, the CGCG contains more fibrous stroma, hemosiderin deposits, infiltrative lymphocytes, and reactive bone formation compared with GCT).

$\mathrm{ABC}$, usually presents in the posterior mandible as a multilocular radiolucency and histologically, characterized by large blood-filled spaces without endothelial lining (but the presented lesion was well defined unilocular radiolucent area and it lacks the large blood-filled spaces without endothelial lining). TBC, typically, little to no tissue is obtained at the time of surgery; therefore, the diagnosis is based primarily on the clinical, radiographic, and intraoperative findings (but in our presented case the final diagnosis was obtained on the basis of histopathological evaluation).

Jaw tumor of HPT/Brown tumor, histopathologically CGCG is identical to that of brown tumor of HPT. HPT is associated with increased levels of calcium, alkaline phosphatase, and parathyroid hormone, and a decreased level of phosphorus (but in this reported case all those serum chemistries were within normal range).
The management of aggressive variant of CGCG can, thus, include en bloc resection or conventional surgery (aggressive curettage) with or without medical adjunctive treatment. ${ }^{(33)}$ In our presented case, the decision to perform the traditional surgical procedure was made on the basis of patient consent, the small size of the lesion. In addition to all the treatment modalities and their potential results that has been fully explained to the patient. This is in agreement with Suárez-Roa et al., $2009^{\left({ }^{(43)}\right.}$ and Tabrizi et al., 2012. (44) But, in disagreement with Munzenmayer J et al., $2013^{(45)}$ who reported that surgical curettage is not an effective therapy for CGCG in young people who show aggressive signs and symptoms.

Recurrences are more common in aggressive lesions with size greater than $2 \mathrm{cms}$ and in patients younger than 20 years of age. ${ }^{(46)}$ In our presented case the size of the lesion was less than $2 \mathrm{~cm}$ and the patient age was 28 years old. This is consistent with Reichart P and Philipsen HP 2004. ${ }^{(47)}$ Although this presented case was treated with traditional surgery (curettage), clinical and radiographic follow-up was done for next two year period without recurrence of the lesion was evident, indicate complete elimination and cure of the lesion. In agreement with Ahmad et al., $2016^{\left({ }^{(4)}\right)}$ and Reddy. $2012^{(29)}$ But inconsistent with Manchanda et al., 2011 ${ }^{(49)}$ who reported that surgical curettage of well-defined localized lesions is associated with a low rate of recurrence. Finally, traditional surgery of an aggressive CGCG was performed without lesion recurrence is attributed to small lesion size, early diagnosis, and high standard surgical curettage that is difficult in the maxillae.

\section{CONCLUSION}

The CGCG is an uncommon, benign and a proliferative non odontogenic lesion of unknown etiology. The diagnosis of central giant cell granuloma is a challenge due to the clinical, radiographic and histopathological similarities with 
other multinucleated giant cell lesions of the jaws. The clinician should always take in the consideration differential diagnosis while examining bony swelling in the oral and maxillofacial region. Nevertheless, its final diagnosis is confirmed by histopathological examination. A correct early diagnosis and complete surgical excision with curettage are effective in the complete cure of oral CGCG and would help to prevent lesion recurrence, especially for young patients with an aggressive well-defined localized small lesions. According to many previous studies, the authors recommended that it would be sensible to start with traditional surgery and proceeding a radical surgery for recurrence lesions. Further studies should be encouraged to clarify the etiopathogenesis of the lesion and how to differentiate between an aggressive and non-aggressive forms of CGCG.

\section{REFERENCES}

1. Yadav S. et al. Recurrent case of central giant cell granuloma with multiple soft tissue involvement. Nati J Maxillofac Surg. 2014; 5(1):60-66.

2. Amita Aditya and Priyam Aditya. Central Giant Cell Granuloma of Jaw with Multiple, Multifocal Recurrences. J Clin Diag Rese. 2016; 10(8): 03-04.

3. De Lange J, Van DA and Klip H. Incidence and diseasefree survival after surgical therapy of central giant cell granulomas of the jaw in The Netherlands: 1990-1995. Head Neck. 2004; 26: 792-5.

4. Neville BW. et al. Oral and Maxillofacial Pathology. 4th ed. Philadelphia: Saunders; 2016. p. 705-40.

5. Papanicolaou P. et al. Increased TNF- $\alpha$, IL- 6 and decreased IL-1 $\beta$ immunohistochemical expression by the stromal spindle-shaped cells in the central giant cell granuloma of the jaws .Med Oral Patol Oral Cir Bucal. 2012; 17 (1):e56-62.

6. Infante-Cossío P. et al. Recurrent central giant cell granuloma in the mandible: Surgical treatment and dental implant restoration. Med Oral Patol Oral Cir Bucal 2007; 12:E229-32.

7. Munde A. et al. Nonsyndromic Synchronous Multifocal Central Giant Cell Granulomas of the Maxillofacial Region: Report of a Case. Journal of Dentistry, Tehran University of Medical Sciences. 2015; 12 (2):157-162.
8. Hosur MB. et al. Clincopathological profile of central giant cell granulomas: An institutional experience and study of immunohistochemistry expression of p63 in central giant cell granuloma. J Oral Maxillofac Pathol. 2018; 22:173-9.

9. Waldron CA and Shafer WG. The central giant cell reparative granuloma of the jaws: an analysis of 38 cases. Am J Clin Pathol. 1966; 45: 437-47.

10. Marina Rolo Pinheiro da Rosa. et al. Central giant cells lesion: Report of a conservative management. Eur J Dent. 2018; 12(2): 305-310.

11. Aarfa Nasim. et al. Idiopathic Bilateral Central Giant Cell Granuloma of Jaw- A Case Report and Brief Review of Reported Cases. J Oral Diag [online] 2017; 02:e20170005.

12. Chandna P. et al. Peripheral and central giant cell lesions in children: Institutional experience at Subharti Dental College and Hospital. Indian J Med Paediatr Oncol. 2017; 38:440-6

13. Cavalcante. et al. Central giant cell granuloma (CGCG) in childhood: surgical treatment by maintaining the tooth germs. RSBO. 2017; 14(1):37-43.

14. Yüzbaşıŏlu. et al. Multidisciplinary approach for the rehabilitation of central giant cell granuloma: A clinical report. J Clin Prac. 2014; 17 (4):528-533.

15. Kamble KA. et al. Central giant cell granuloma: A case report with review of literature. J Indian Acad Oral Med Radiol. 2016; 28:98-101.

16. Ebrahimi H. et al. Central giant cell granuloma of the posterior maxilla: A case report. J Dent Res Dent Clin Dent Prospects. 2008; 2:71-5.

17. Tenore G. et al. The central giant cells granuloma of the mandible: a report of two cases and a review of the literature. Senses Sci. 2014; 1:30-38.

18. Gerzanic. et al. Central Giant Cell Granuloma Resistant to Calcitonin Nasal Spray: A Case Report. Anaplastology. $2013 ; 2(5): 1-3$

19. Patloth T and Reddy SJ. Surgically Treated Central Giant Cell Granuloma in Six-Year-Old Child: A Case Report. Int J Clin Pediatr Dent. 2013; 6(2):146-149.

20. Chawla C. et al. Central giant cell granuloma: A case report. A J Diagn Imaging.2017; 2 (1):17-20.

21. Baskaran P. et al. Aggressive central giant cell granuloma of the mandible, a diagnostic dilemma. J Oral Maxillofac Radiol. 2015; 3:88-91. 
22. Ustaad F. et al. Aggressive Variant of Central Giant Cell Granuloma. Austin J Surg. 2018; 5(4): 1136.

23. Kaban LB. et al. Antiangiogenic therapy with interferon alpha for giant cell lesions of the jaws. J Oral Maxillofac Surg. 2002; 60:1103-11.

24. P. Garg. et al. A central giant cell granuloma in posterior part of maxilla - A case report International Journal of Surgery Case Reports. 2017; 30: 222-225.

25. Andre Caroli Rocha. et al. Denosumab in the treatment of maxillary central giant cell granuloma: report of two new cases. Oral Surg Oral Med Oral Pathol Oral Radiol J.2020; 129 (1): 18-19.

26. Israel L. Cavalcante. et al. Quantification of bone gain in central giant cell granuloma of the jaws submitted to intralesional corticotherapy. J Bras Patol Med Lab. 2018; 54(3): 183-188.

27. Rachmiel A. et al. Combined treatment of aggressive central giant cell granuloma in the lower jaw. J Craniomaxillofac Surg. 2012; 40:292-7.

28. Sandhya. et al. Multifocal Central Giant Cell Granuloma A Case Report. Iran J Pathol. 2016; 11(3): 276 - 280.

29. Reddy GV. et al. Surgical management of aggressive central giant cell granuloma of maxilla through Le Fort I access osteotomy. J Clin Imaging Sci 2012; 2(1):1-5.

30. Shafer WG, Hine MK, Levy BM. Textbook of Oral Pathology. 7th ed. Philadelphia: Saunders 2012; p.137.

31. Kaur N, Kohli T and Chhina AK. Central giant cell granuloma: A diagnostic predicament. J Adv Med Dent Scie Res 2015; 4(1):90-95.

32. Bataineh $\mathrm{AB}, \mathrm{Al}-\mathrm{Kh}$ ateeb $\mathrm{T}$ and Rawashdeh MA. The surgical treatment of central giant cell granuloma of mandible. J Oral Maxillofac Surg. 2002; 60: 756-761.

33. Mariam Mezzour, Karima Elharti and Wafaa Elwady. An aggressive central giant cell granuloma treated successfully by conventional surgery. Inte J Appl Dent Scie. 2017; 3(4): 344-347.

34. A. Bonolis. et al. Central giant-cell granuloma located in the mandibular symphyseal region of a child. J Oral Med Oral Surg 2018; 24:53-56.

35. Elitsa G. Deliverska and Hristo D. Stoyanov. Surgical treatment and reconstruction for central giant cell granuloma of mandible- case report and literature review. J IMAB. 2013; 19(4):407-410.
36. Priyadharshini I K. et al. An unusual presentation of aggressive central giant cell granuloma. J Adva Clin \& Rese Insi. 2014; 2: 53-56.

37. Dangore-Khasbage S. et al. Unusual aggressive behavior of central giant cell granuloma following tooth extraction. World J Stomatol. 2015; 4(1): 29-34.

38. Faitaroni LA. et al. Differential diagnosis of apical periodontitis and nasopalatine duct cyst. J Endod. 2011; 37:403-10.

39. Rodrigo Gadelha Vasconcelos, Marcelo Gadelha Vasconcelos and Lélia Maria Guedes Queiroz. Peripheral and central giant cell lesions: etiology, origin of giant cells, diagnosis and treatment. J Bras Patol Med Lab. 2013; 49(6):446-452.

40. Prathibha Prasad and Sura Ali Bayati. Nonaggressive Central Giant Cell Granuloma: A Case Report. RRJDS. 2014; 2 (1):73-78,

41. Bahbah S. et al. Central Giant cell granuloma in a child - Case report. Int. J. Odontostomat.2016 ; 10(3):393-397.

42. MK Gupta, SG Naidu and VJ Maheshwari. Giant Cell Lesion of the Jaw: A Case Report in a Child. P J Scie Rese. 2011; 4(1):63-67.

43. Suárez-Roa et al. Interventions for central giant cell granuloma (CGCG) of the jaws. Cochrane Database Syst Rev. 2009; 4:CD007404.

44. Tabrizi et al. Can calcitonin nasal spray reduce the risk of recurrence of central giant cell granuloma of the jaws? A double-blind clinical trial. Int J Oral Maxillofac Surg. 2016; 45:756-759.

45. Munzenmayer J. Central giant cell granuloma of the mandibular condyle. Case-report. Rev Clin Peri Impl Reha Oral.2013; 6(2):83-86.

46. Bangi BB. et al. Medical management of a case of central giant cell granuloma masquerading as a periapical pathosis. J Indian Acad Oral Med Radiol. 2015; 27:152-5.

47. Reichart P, Philipsen HP. Odontogenic Tumors and Allied Lesions. 6th ed. London: Quintessence Publishing Co, Ltd; 2004. P.105-15.

48. Ahtesham Ahmad. et al. Aggressive Central Giant Cell Granuloma Mimicking Peripheral Giant Cell Granuloma - A Rare Case Report and Review of Literature. Int J Curr Microbiol App Sci. 2016; 5(2): 263-266.

49. Manchanda A. et al. Aggressive central giant cell granuloma mimicking giant cell tumor. IJCRI. 2011; 2(2):5-10. 